\title{
Research on the Genesis and Development of Danxia Landform in the South Sichuan
}

\author{
Hongying Li ${ }^{1,2}$, Lan Liu ${ }^{1}$ \\ ${ }^{1}$ School of Economics, Sichuan University of Science \& Engineering, Zigong, China \\ ${ }^{2}$ Sichuan Key Provincial Research Base of Intelligent Tourism, Yibin, China \\ Email: lihongying314@163.com
}

How to cite this paper: Li, H.Y. and Liu, L. (2018) Research on the Genesis and Development of Danxia Landform in the South Sichuan. Journal of Geoscience and Environment Protection, 6, 12-24. https://doi.org/10.4236/gep.2018.68002

Received: July 5, 2018

Accepted: July 31, 2018

Published: August 3, 2018

Copyright ( 92018 by authors and Scientific Research Publishing Inc. This work is licensed under the Creative Commons Attribution International License (CC BY 4.0).

http://creativecommons.org/licenses/by/4.0/

(c) (i) Open Access

\begin{abstract}
The South Sichuan is one of the areas in China famous for Danxia Landform. Danxia Landform in the South Sichuan is characterized by wide distribution and square shaped hills. However, there is no systematic research on the genesis of those Danxia Landforms at present. Based on the study of spatial distribution and the genesis of the Danxia Landforms in the South Sichuan, we discovered that the lithostratigraphy, regional tectonic, crustal uplift and external forces contribute together to the formation of the Danxia Landform. On the basis of learning the development experiences from famous scenic spots and the updated national policies and regulations, proposals were made to boost the development of Danxia Landform resources in the South Sichuan by excavating its historic, cultural, natural and scientific connotation in the form of educational tourism.
\end{abstract}

\section{Keywords}

Danxia Landform, Resource Genesis, Educational Tourism, South Sichuan

\section{Introduction}

Danxia Landform, a concept first theorized by Chinese scholars, refers to various landscapes that consist of red beds characterized by upright-shaped peaks [1]. It has a counterpart abroad, red-bed. Danxia Landforms are widely distributed in China, thus Chinese scholars were pioneers to conduct researches on Danxia Landform. Danxia Landform has been one of the significant landscapes and hot topics in tourism and geological researches. Danxia Landform in China, integrated by scenic areas of Taining in Fujian, Langshan in Hunan, Danxiashan in Guangdong, Longhu Mountain in Jiangxi, Jianglang Mountain in Zhejiang and Chishui in Guizhou, has been successfully inscribed into the World Heritage List in 2010, which marked that the concept of Danxia Landform has been accepted 
by the rest of the world. Researches on Danxia Landform in the domestic mainly concentrated on the following aspects:

1) Definition and classification

The definition of Danxia Landform was proposed last century, while the definition was expanded by Liu Shangren and Liu Ruihua from a narrower land facies to broader sedimentary rocks from the viewpoint of lithology, and from red-cliff to cliff group from the viewpoint of landform [2]. Zhao Ting et al. defined the Danxia Landform from both narrow (typical) and broad (expanded) senses respectively based on accomplishment of tectonic movement and neotectonics researches [3].

2) Distribution and field research

Danxia Landforms are mainly distributed in the southeast, southwest and northwest parts in China [4], with 1003 spots in 28 provinces [5]. Besides field research, remote sensing and GIS technology also have been applied in Danxia Landform resources investigation, and now detailed criteria or marks for visual interpretation are available [6].

3) Experimental geomorphology research

This is a new and key trend of the Danxia Landform research. Crustal lift speed, geochronology, cliff retreating rate and erosion rate were discussed by Huan Jin through sample collecting and relevant experiments [7], which is a significant attempt for transferring Danxia Landform research from qualitative description to quantitative research. The forming process of Danxia Landform in Qiyun Mountain has been revealed by data analyzing and experiment based on field survey, lithological and structural data [8]. Besides, K-Ar dating result of diabase bedded in the red stratum has been obtained, and the result constrained the uplift time of the basin to the late Cretaceous (77.89 $\pm 2.6 \mathrm{Ma})$ [9].

4) Exploration and protection of Danxia Landform heritage

In-depth exploration and protection of Danxia Landform are the final purpose of the researches. Chen et al. [10] discussed problems about the exploration of Danxia Landform resource in some scenic areas, including regional natural and cultural resources status, landscape aesthetics, reasonable protection and exploration of landscape resource, development of tourism industry and regional tourism development strategies. Bao Jigang and Peng Hua analyzed the practicability of exploring the Yangyuan Column at the scenic spot of Danxia Mountain in Guangdong [11], which is conducive to expanding the impact of Danxia Landform and disseminating the image of the scenic area and set an example for the afterward researchers [11]. Zhou Xuejun discussed the discrepancies between Danxia Landforms in the north and south of China, and pointed out that exploration of Danxia Landform in the north should emphasize its culture, while in the south the integrated natural and cultural features should be presented with priority [12].

5) Review and research progress

Peng [13] [14] made an overall review on research progress of Danxia Landform in last century, and suggested that the later researchers should enhance 
fundamental theory research and communicate with international researchers. Ouyang Jie [15] made a comparison between Danxia Landform research both in domestic and abroad, and came up with helpful advices for conducting further researches on Danxia Landform.

Researchers abroad conducted rare research on Danxia Landform. International geological circle named Danxia Landform red bed. Overseas scholars have conducted researches on the red bed to understand the strata sequence, deposit system, geological setting and condition of deposit mineral products [16] [17] [18]. Researches on sandstone landform all over the world also refer to some Danxia Landform [19] [20]. In recent years, domestic researchers get their manuscripts published in international journals with a view to improve the publicity of Danxia Landform in China [21] [22] [23].

The south of Sichuan basin and its surrounding areas are where the Danxia Landform intensively distributed in China, north to the Rongxian, south to the Gulin and Chishui, covering an area of $1340 \mathrm{~km}^{2}$ [5] [24]. The southern part of Sichuan basin and its surrounding area are featured by incised ravines and upright-shaped escarpments, which is of typical significance in domestic even all over the world. However, researches on the Danxia Landform still stop at the starting stage, especially remaining blank on the genesis, with low-level exploration and weak influence. Hence, this paper aims to explore the genesis of Danxia Landform based on field work in the South Sichuan for the first time. On the basis of understanding the genesis of Danxia Landform, we propose possible advices for exploring and utilizing the geological resources by excavating its historic, cultural, natural and scientific connotations.

\section{Distribution of Danxia Landform in the South Sichuan}

Traditionally, the South Sichuan consists of five cities, Yibin, Leshan, Zigong, Luzhou and Neijiang, respectively. But Danxia Landforms are distributed unevenly in the aforesaid cities. Most Danxia Landforms are distributed in Luzhou, Yibin and Leshan, such as the well known scenic areas Bamboo-sea, Leshan Giant Buddha, Huangjing Laolin, Tianxiandong, Danshan, and some other untapped scenic areas. However, only Danxia Landforms in Luzhou are highly explored, with nine famous scenic spots. Relatively, exploration and utilization of the Danxia Landform resource in Yibin and Lushan is immature, and a large portion of Danxia Landform resources are awaiting further development (Table 1). A few Danxia Landforms are distributed in Zigong, such as Feilongxia and Jinsha Alsophila Valley. But rare Dianxia landform has been found in Neijiang by now.

\section{Genesis of Danxia Landform Resource in the South Sichuan}

Generally, Danxia Landform features red in colour and with sharp cliff. And the colour is controlled by the colour of strata where the landform lies. Thus, the red 
Table 1. Distribution of Danxia Landform in southern Sichuan.

\begin{tabular}{|c|c|c|c|}
\hline City & Scenic area & Location & Honor \\
\hline \multirow{15}{*}{ Yibin } & Bamboo Sea & Changning and Jiang'an & National Four-Star Scenic Area \\
\hline & Qi Donggou & Changning & National Four-Star Scenic Area \\
\hline & Baxianshan Standing Buddha & Pingshan County & National Three-Star Scenic Area \\
\hline & Shengtian Hongyan Mountain & Gaoxian & National Three-Star Scenic Area \\
\hline & Kejiu Hongyan Mountain & Gaoxian & National Two-Star Scenic Area \\
\hline & Yuntai Mountain & Nanxi District & Provincial Forest Park \\
\hline & Shicheng Mountain & Yibin County & Provincial Forest Park \\
\hline & Danshan Bishui & Cuiping District & Provincial Key Cultural Relics Protection Unit \\
\hline & Baizhuhai, Renhe & Jiang'an County & \\
\hline & Hongyanwo,Shigu & Nanxi District & \\
\hline & Shuanghe Danxia & Pingshan County & \\
\hline & Huahu Tianyuan & Lingang development zone in the Cuiping District & \\
\hline & Baojiayan & Yibin County & \\
\hline & Qiaoba Huanya & Conjunction part of Pingshan and Mabian & \\
\hline & Huishigou & Cuiping District & \\
\hline \multirow{11}{*}{ Leshan } & Leshan Giant Buddha & Shizhong District & $\begin{array}{l}\text { National Four-Star Scenic Area; } \\
\text { World Cultural \& Natural Heritage }\end{array}$ \\
\hline & Baogao Temple & Emeishan City & $\begin{array}{l}\text { National Four-Star Scenic Area; } \\
\text { World Cultural \& Natural Heritage }\end{array}$ \\
\hline & Zhuhai Danxia, Muchuan & Muchuan County & $\begin{array}{l}\text { National Forest Park; National } \\
\text { Three-Star Scenic Area }\end{array}$ \\
\hline & Qianfoyan & Jiajiang County & $\begin{array}{c}\text { National Key Cultural Relics Protection Unit; } \\
\text { National Three-Star Scenic Area }\end{array}$ \\
\hline & Xiaosanxia, Pingqiang & Shizhong District & Provincial Scenic Area \\
\hline & Mabian Danxia & Mabian County & \\
\hline & Liaoqingyan & Muchuan County & \\
\hline & Yunfeng Mountain & Jianwei County & \\
\hline & Ziyun Mountain & Jianwei County & \\
\hline & Dayantou & Jianwei County & \\
\hline & Biyunshan & Jiajiang County & \\
\hline \multirow{2}{*}{ Zigong } & Feilongxia & Ziliujing District & National Two-Star Scenic Area; \\
\hline & Jinsha Alsophila Valley & Rongxian County & World Geopark \\
\hline \multirow{9}{*}{ Luzhou } & Huangjin Laolin & Gulin County & National Four-Star Scenic Area \\
\hline & Tianxiandong & Naxi District & National Four-Star Scenic Area \\
\hline & Qingxigu & Naxi District & National Four-Star Scenic Area \\
\hline & Fobao Scenic Area & Hejiang County & $\begin{array}{l}\text { World Forest Park; } \\
\text { National Three-Star Scenic Area }\end{array}$ \\
\hline & Huagaoxi Nature Reserve & Xuyong County & National Nature Reserve \\
\hline & Fangshan & Jiangyang District & National Three-Star Scenic Area \\
\hline & Danshan & Xuyong District & Provincial Scenic Area \\
\hline & Dongwo Valley & Longmatan District & National Three-Star Scenic Area \\
\hline & Bijiashan & Hejiang County & National Two-Star Scenic Area \\
\hline
\end{tabular}

Data from tourism development committees of the four cities. 
strata are the material basis of the Danxia Landform. The genesis of sharp cliff is rather complicated, but some large-scale faults are considered the primary controlling factors, and then the crust uplift and external forces. Hence, we will discuss the genesis of Danxia Landform in the South Sichuan from the points of strata, regional structure, crust uplift and external forces.

\subsection{Strata}

The red stratum where Danxia Landform developed is called red bed by overseas scholars. Most red strata in China formed in the Mesozoic and Cenozoic, and those exposed in Sichuan are composed by lower Triassic, Jurassic and Cretaceous strata [24]. The Sichuan Basin had been in a sedimentary environment of large inland lake basin from the upper Triassic to the upper Cretaceous when red sediments were laid. The feldspar quartz sandstone is the chief component of the Danxia Landform in the South Sichuan (Figure 1). However, based on detailed field work, we found that those who are worthy of developing usually form in Cretaceous strata (each pentagram in Figure 1 represents a developed scenic spot or the one worthy of developing).

\subsection{Structure}

Regional structure is the main factor that gives rise to the Danxia Landform and affects its evolution. Large-scale regional structure controls the scale and distribution of Danxia Landform, while small-scale structure decides its appearance and form. When come to the regional structure controlling the formation of Danxia Landform, it usually refers to:

1) Bedding

Bedding is one of the primary structures. The red bed where Danxia Landform developed usually has horizontal or near-horizontal bedding stretching for tens of kilometres. Compared with horizontal or near-horizontal stratum, it is much easier to erode tilted stratum with higher angle, so Danxia Landform rarely developed in tilted strata. That is why strata where Danxia Landform developed in the South Sichuan commonly have horizontal bedding (Figure 2(a)) or lower angle which rarely exceeds 30 (Figure 2(b)).

2) Joints

Joints may occur in sets of parallel regularly spaced fractures and several sets may occur in the same rock, giving a conspicuous blocky appearance to an outcrop. Commonly, the formation of cliff and sharp-shaped Danxia Landform is related to vertical joints, while quadrate or house-like Danxia Landform is controlled by several joints sets which cutting each other. For example, house-like Danxia Landform at the Tianxiandong scenic area (Figure 2(c)) in Luzhou City is controlled by two joints cutting each other. The two joints cut the original huge rock to form fractures along the joint planes that are usually too feeble to stand prolonged weathering. Thousands or millions of years later, the soft components were erodes away or collapsed, while the hard part was left to form quadrate or house-like landform. 


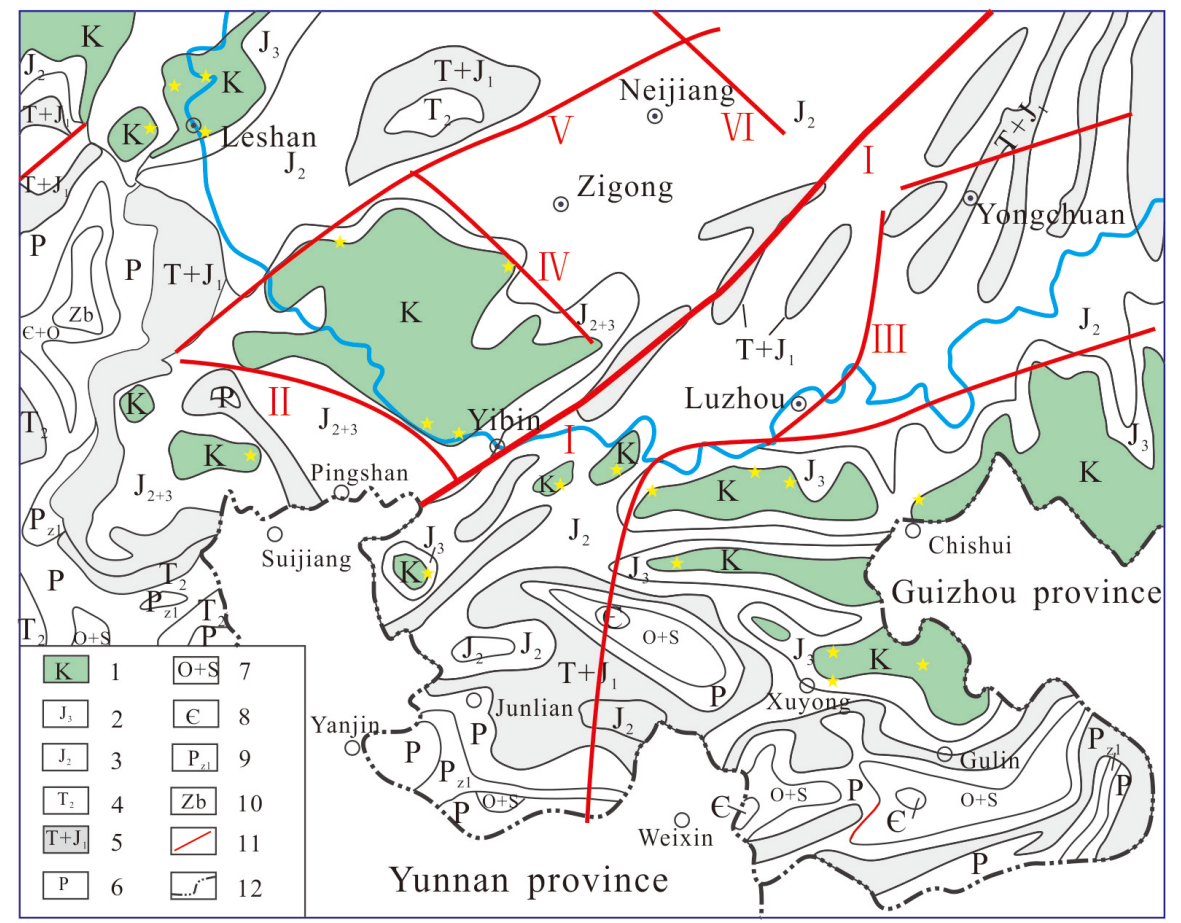

Figure 1. Distribution of strata and regional faults in the South Sichuan.
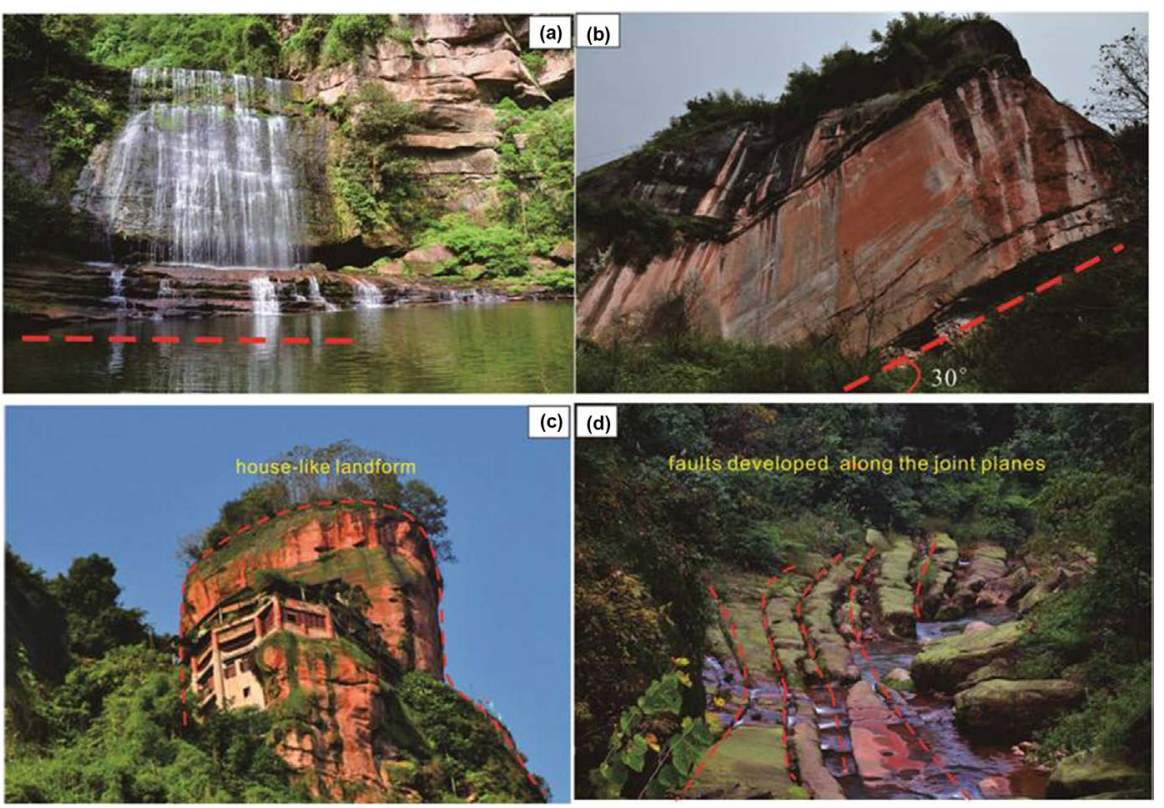

Figure 2. Outcrops of Danxia Landform in the South Sichuan. (a) Huangjing Laolin Bajiedong; (b) Danshan, (c) Tianxiandong, (d) Huagao Spring.

\section{3) Faults}

A fault is a planar fracture across which the rock has been displaced in a direction which is generally parallel to the fracture plane. Faults widely develop in the crust, thus it is one of the common structures in nature. Large-scale fault usually decides the framework of regional geology, and some are large enough to 
cut through the crust and gives rise to the basement rift. As Figure 1 shows, strata and Danxia Landform in the South Sichuan obviously controlled by large-scale faults, especially by the basement rift. Huayingshan Fault starts from Dazhou to the north and stretches to Rongchang and Yibin to the south [25], with a length of approximate $600 \mathrm{~km}$, controlling the deposit of Triassic and lower Jurassic strata and dividing the Cretaceous red bed in the South Sichuan into two parts. On the left side, Cretaceous strata are mainly distributed in the counties of Yibin, Muchuan, Jianwei and the central part of Leshan City, while on the right side, the Cretaceous strata concentrated in the counties of Jiang'an, Changning, Xuyong and Hejiang. The recent earthquakes occurred in Yibin is considered relevant to the movement of Huayingshan fault. Other faults, such as Emei-Yibin fault zone, Xinglongchang fault and Rongxian-Weiyuan fault are also controlling the formation of Danxia Landform in Yibin and Zigong.

During the formation process, like the joints, faults also play important role in controlling the appearance of Danxia Landform. As Figure 2(d) shows, serial deep vertical faults developed in Huagao Spring State Reserve Area, which cut the horizontal red strata into pieces and give rise to several sallow valleys. It is exactly where the Danxia Landform developed, indicating that the fault do control the appearance and distribution of the Danxia Landform.

\subsection{Crust Uplift and Evolution}

Crust uplift after the formation of red bed constrains the development and evolution of Danxia Landform. The crust uplift carried deeply-buried rocks to the erosion basis. Due to the strong uplift, hills were cut by meandering rivers and formed steep slopes along both sides of the valleys gradually. Probably millions of years later, eminent Danxia Landform finally formed. In recent years, scholars prefer to adopt fission track to calculate the uplift pace, and the fission track age of minerals is considered the time when the mineral cooled due to the uplift of crust, because the mineral gets cooler when it is carried to the shallower depth as the uplift process. According to previous researches, since the late Cretaceous, the surface of Sichuan basin has suffered different erosion due to the collision and compression among plates, early slow uplift and cooling process ( $80 \mathrm{Ma}-20$ $\mathrm{Ma}$ ) and the late fast uplift erosion process( 20 Ma-today), respectively. The erosion speed of the different parts in the Sichuan basin significantly differs from each other. In space, the erosion speed gets faster from the northeast to the southwest. Since the late Cretaceous, Sichuan basin has been erased at least 2500 $\mathrm{m}$, and in some parts over $4000 \mathrm{~m}$ [26]. It is exactly the intensive uplift that carried the late Cretaceous red strata to the erosion base level, getting the red strata exposed by weathering and running water, which formed the basic style and features of Danxia Landform.

\subsection{External Forces}

For the formation of Danxia Landform in the South Sichuan, external forces 
mainly refer to weathering, running water and gravity.

Based on detailed field work, we found that the red strata in the South Sichuan are different in lithology. They consist of hard sandstones, glutenites bedded by mudstone, and soft siltstones. The hard stratum commonly is cemented by calcareous and ferruginous, with weak hydroscopicity but strong load intensity, thus it is hard to be eroded, while the soft stratum is mainly cemented by mud, with strong hydroscopicity but weak load intensity, which makes it easier to be eroded by weathering and rainfall [27]. Several outcrops in Tianxiandong in Luzhou indicate that how the weathering and rainfall erosion worked together to give rise to the formation of the caves in red strata. As Figure 3 shows, it is the soft stratum first started to crack because of endogenetic factors (Figure 3(a)), then the soft sediments was carried away by erosion and left many small holes (Figure 3(a)), and then the small holes grew bigger due to the continuous erosion and collapse (Figure $3(c)$ ), and finally the bigger holes connected with each other along the soft stratum and formed large scaled bedding cave (Figure 3(d)).

The lateral erosion of running water also contributes to the formation of large scale horizontal caves at the foot of mountain, while the groundwater erosion is conducive to forming cliff and valley. Bedding caves caused by weathering and running water made the rocks above the cave hang in the air and the rock finally collapsed due to the gravity.

\section{Development of Danxia Landform Resource in the South Sichuan}

Danxia Landform originated from China, with longer development history compared with red beds in other countries. There have been six scenic areas famous for Danxia Landform qualified as world nature heritages, and they are Taining in Fujian, Langshan in Hunan, Danxiashan in Guangdong, Longhu Mountain in Jiangxi, Jianglang Mountain in Zhejiang and Chishui in Guizhou. Besides, Wuyishan in Fujian, Zhangye in Gansu, Qiyun Mountain in Anhui, Chengde in Hebei, Leshan Giant Buddha and Bamboo Sea in the South Sichuan are also well known both in domestic and abroad for their typical Danxia Landform sceneries. To explore the Danxia Landform resource in the South Sichuan, we should learn from the previous experiences.

Danxia Landform is well known for its solemn appearance, so most scenic areas famous for Danxia Landform in China have become the holy lands of religion (Table 2).

However, so many scenic areas have been over-commercialized that the governments at different levels have issued regulation on governing the commercialized Buddhism and Taoism at the scenic areas. Business capital is strictly prohibited from entering into religion domain. And no large scaled religion-related statue or sculpture is allowed in scenic areas any more. Thus, we should concentrate on the local history, culture and scientific values when explore the tourism resources. 


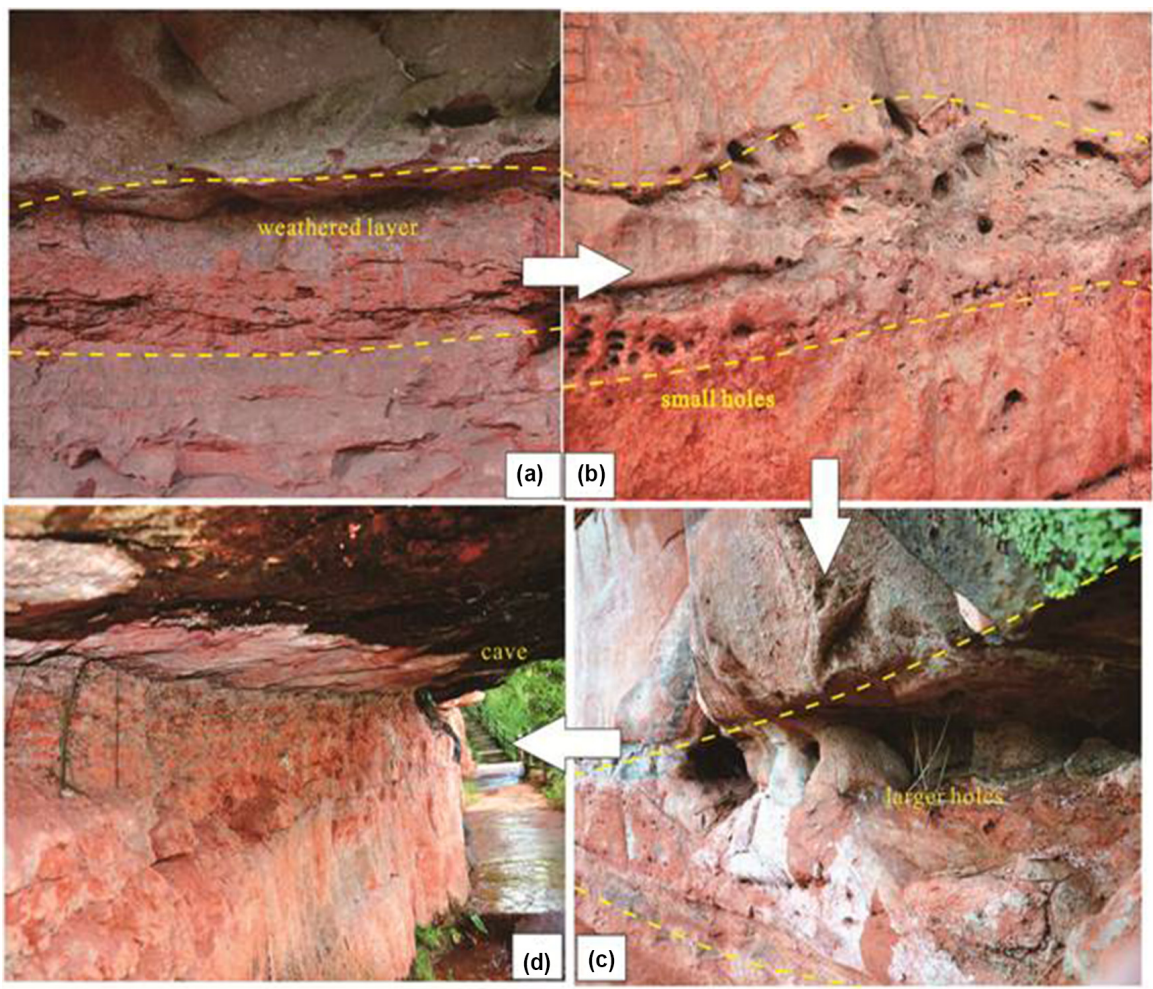

Figure 3. Forming process of caves in the red bed.

Table 2. Human landscapes and culture heritages at the typical Danxia Landform scenic areas.

\begin{tabular}{|c|c|c|c|}
\hline Province & Scenic area & $\begin{array}{c}\text { Typical Human Landscape and } \\
\text { Culture Heritage }\end{array}$ & Features \\
\hline Jiangxi & $\begin{array}{l}\text { Longhu } \\
\text { Mountain }\end{array}$ & $\begin{array}{l}\text { Shangqinggong, Tianshuaifu, } \\
\text { Suspending coffin group }\end{array}$ & Birthplace of Chinese Taoism \\
\hline Fujian & $\begin{array}{c}\text { Wuyi } \\
\text { Mountain }\end{array}$ & $\begin{array}{l}\text { Wuyigong, Taoist temple at the } \\
\text { Taoyuandong }\end{array}$ & $\begin{array}{c}\text { Holy mountain of Confucianism, } \\
\text { Buddhism and Taoist }\end{array}$ \\
\hline Anhui & $\begin{array}{l}\text { Qiyun } \\
\text { Mountain }\end{array}$ & $\begin{array}{c}\text { Taisugong, Yuehuajie, } \\
\text { Zhenxiandong, Fangla Village }\end{array}$ & $\begin{array}{c}\text { One of the Four Famous Mountains of } \\
\text { Taoism; the sits where Fangla peasant } \\
\text { revolted }\end{array}$ \\
\hline Fujian & Taining & Ganluyan Temple & $\begin{array}{c}\text { Suspending temple built along the cliff } \\
\text { and cave }\end{array}$ \\
\hline Hunan & $\begin{array}{l}\text { Langshan } \\
\text { Mountain }\end{array}$ & Bajiao Village, Yuntai Temple & $\begin{array}{l}\text { The sits where peasant revolted at the } \\
\text { end of Qing dynasty }\end{array}$ \\
\hline Guangdong & $\begin{array}{c}\text { Danxiashan } \\
\text { Mountain }\end{array}$ & Jinshiyan Temple, Ximei Village & $\begin{array}{l}\text { Taoist rites for female members; } \\
\text { Temple built in Qing dynasty }\end{array}$ \\
\hline Zhejiang & $\begin{array}{l}\text { Jianglang } \\
\text { Mountain }\end{array}$ & $\begin{array}{l}\text { Kaiming Temple, Jianglang } \\
\text { Academy Cliff inscriptions }\end{array}$ & $\begin{array}{l}\text { Temple built in Song dynasty and } \\
\text { Confucianism buildings }\end{array}$ \\
\hline Sichuan & $\begin{array}{l}\text { Leshan } \\
\text { Giant } \\
\text { Buddha }\end{array}$ & $\begin{array}{l}\text { Leshan Giant Buddha, Wuyou } \\
\text { Temple, LingyunTemple }\end{array}$ & The highest cliff sculpture in China \\
\hline Sichuan & Bamboo sea & $\begin{array}{c}\text { Longyin Temple, Xianyu Cave, } \\
\text { Tianbao Village }\end{array}$ & Grotto and ancient pathway on the cliff \\
\hline
\end{tabular}




\subsection{Exploration of Historic and Cultural Connotation}

Besides religion-related scenery, Danxia Landform also contains abundant historic and cultural connotation, such as cliff tomb and cliff dwelling. Both the Mahao Cliff Tombs at the Leshan Giant Buddha scenic area and the Huangsanya Cliff Tombs at the Danshan Bishui scenic area in Yibin were built in the Han dynasty, indicating the ancient local residents' living habits. In addition, cliff tombs at the Shichengshan are tombs built by the southwestern minorities from the Song dynasty to Ming dynasty, with remarkable significance in the appreciation and research of the culture of southwestern minorities.

In history, it was hard to conquer gate tower built on or between the mountains, because Danxia Landform is characterized by flat top and cliffy side. That is why there are so many ancient cities or villages ruins in the South Sichuan, such as Sangui Jiuding City at the Leshan Giant Buddha scenic area, Ziyun City at the Jianwei and Tianba village at the Bamboo Sea in the South Sichuan. What's more, the calligraphy work caved on the cliffs, historical figures, minority customs, folk customs, diet habits and culture creations are valuable cultural resources awaiting developing. If the development of Danxia Landform can be integrated with the development of the aforementioned cultural resources, it will be conducive to enhancing the cultural soft power, improving the attractiveness of the scenic areas and disseminating and protecting local history and culture.

\subsection{Exploration of Natural and Scientific Connotation}

As natural scenery, Danxia Landform is of ample scientific connotation, referring to geography, geomorphology, geology, ecology, biology, environmentology and agronomy. New tourism products can be introduced by integrating the above scientific connotations with the nature sightseeing based on the analysis of tourists' demands. That is exactly what is neglected by the decision makers nowadays.

How to excavate its geological connotation? It mainly refers to finding out the genesis of the red bed, formation time, forms of Danxia Landform, development mechanism, evolution, and the causes of the birth and death of palaeobios, the current situation and conservation of earth environment. The scientific connotation can be presented directly and vividly by using new information technology, such as VR and AR, which will not only provide the tourists with more smarter and comfortable experience but also foster awareness of seeking truth and protecting ecoenvironment.

To excavate the ecological connotation, we need to ravel out all plants and animals living in the scenic area, to tell tourists the species of special plants and their unique applications, to tell the tourists the name of different animals and their rarities, to inform tourists the environment destruction and enhance awareness of environment pretention. Scientific education and nature science experience can realize through plants exhibition, festivals, setting up plant varieties introduction and biology museum. In addition, we can explore the nearby 
agricultural resource and healthcare resources to operate leisure agriculture tourism, healthcare and hobby farm to prolong the sojourn time and further to improve economic returns.

To excavate the scientific connotation, we need to take the educational tourism into consideration. Educational tourism a tourism form supported by the state with large potential and is considered a new growth point. The development of Danxia Landform resource in the South Sichuan should be on based on the educational demand of tourists, which means various educational products should be developed according to different targeted customers. For example, for primary or middle school students, tour related to folk culture or local customs should be introduced, but for college students or adults, educational tourism related to professional subjects should be introduced. In recent years, the number of educational tourism consumers has kept growing with the implementation of relevant regulations on the educational tourism. The integration of Danxia Landform development and educational tourism will contribute to improving the scientific and cultural connotation at the scenic areas and keeping bring tourists in.

\section{Conclusion}

Danxia Landform, as a concept first named by Chinese scholars, is a rare tourism resource. It has become more popular after six typical Danxia Landform scenic areas were successfully included on the World Heritage List in 2010. The forming of Danxia Landform resource in the South Sichuan is the consequence of the endogenetic and exogenetic factors. Endogenetic factor refers to the nature of the strata or sediment. Exogenetic factors refer to structure like bedding, joints and fault, crust uplift, weathering, running water, rainfall erosion and gravity. Research on the genesis of Danxia Landform can be conducive to excavating its scientific connotation to develop educational tourism in this area. Beside, historical and cultural connotations should be considered when exploring and utilizing Danxia Landform resource.

\section{Acknowledgements}

The authors would like to acknowledge the supports from Sichuan University of Sciences \& Engineering (2017RCSK01), Scientific Research Fund of Sichuan Provincial Education Department (18SB0492), Sichuan Key Provincial Research Base of Intelligent Tourism (ZHYR18-02) and Industry Transformation and Innovation Centre of Zigong Social Sciences Association (2017CYZX005).

\section{Conflicts of Interest}

The authors declare no conflicts of interest regarding the publication of this paper.

\section{References}

[1] Huang, J. (1999) On the Distribution of Danxia Landforms in China. Economic 
Geography, No. 19, 31-35.

[2] Liu, S.R. and Liu, R.H. (2003) On the Conception of Danxia Landform. Journal of Mountain Science, No. 6, 669-674.

[3] Zhao, T., Zhao, X., Peng, H. and Hou, R.F. (2014) A Tentative Discussion on the Definition and Classification of Danxia Landform. Acta Geoscientica Sinica, No. 3, 375-382.

[4] Qi, D.L., Yu, R., Zhang, R.S., Ge, Y.J., Li, J.L. (2005) On the Spatial Pattern of Danxia Landform in China. Acta Geographic Sinica, No. 1, 41-52.

[5] Huang, J., Chen, Z.Y., Qi, D.L. (2015) Study on Distribution of Danxia Landform in China (First). Mountain Research, No. 4, 385-396.

[6] Liu, L.Q., Guo, F.S. and Zeng, X.H. (2007) Study on the Danxia Landform Geomorphologic Landscape with Remote Sensing Technology. Journal of East China Institute of Technology, No. 3, 247-251.

[7] Huang, J. (2004) Quantitative Survey of Several Important Issues Concerning the Formation of the Danxia Landforms. Tropical Geography, No. 2, 127-130.

[8] Zhu, C., Peng, H., Li, S.C., Huang, L.Y., Zheng, C.G., Xiang, F.S., Sun, Y.F., Tang, Y.S., Hu, J.Y., Zhu, G.H., Lv, J.J. and Cheng, G.H. (2005) Danxia Landform Genesis on Qiyun Mountain, Anhui Province. Acta Geographica Sinica, No. 3, 445-455.

[9] Zhu, C., Peng, H., Li, Z.X., et al. (2009) Age and Genesis of the Danxia Landform on Jianglang Mountain, Zhejiang Province. Acta Geographica Sinica, 19, 21-32. https://doi.org/10.1007/s11442-009-0615-x

[10] Chen, C.K., Gao, Y.G., Yu, K.J. and Peng, H. (1990) A Study on Tourism Development of the Danxia Landform Scenic District. Acta Geographica Sinica, No. 3, 284-294.

[11] Bao, J.G. and Peng, H. (1995) A Study on the Expansion Development of Tourist Resorts-Taking Yangyuan Section, Danxia Scenic Spot as an Example. Scientia Geographica Sinica, No. 1, 63-70.

[12] Zhou, X.J. (2003) A Study on North-South Differences of the Danxia Landform Pattern and Its Tourism Values in China. Journal of Mountain Science, No. 2, 180-186.

[13] Peng, H. (2000) A Survey of the Danxia Landform Research in China. Scientia Geographica Sinica, No. 3, 203-211.

[14] Peng, H., Pan, Z.X., Yan, L.B., Simonson, S. (2013) A Review of the Research on Red Beds and Danxia Landform. Acta Geographica Sinica, No. 9, 1170-1181.

[15] Ouyang, J., Zhu, C. and Peng, H. (2011) A Contrast Introduction to Danxia Landforms from World-Wide References for Similar Landforms. Scientia Geographica Sinica, No. 8, 996-1000.

[16] Larson, E.E. and Walker, T.R. (1975) Development of Chemical Remanent Magnetization during Early Stages of Red-Bed Formation in Late Cenozoic Sediments, Baja California. Geological Society of America Bulletin, 86, 639-650. https://doi.org/10.1130/0016-7606(1975)86<639:DOCRMD>2.0.CO;2

[17] Besly, B.M. and Fielding, C.R. (1989) Palaeosols in Westphalian Coal-Bearing and Red-Bed Sequences, Central and Northern England. Palaeogeography, Palaeoclimatology, Palaeoecology, 70, 303-330. https://doi.org/10.1016/0031-0182(89)90110-7

[18] Racey, A. and Goodall, J.G.S. (2009) Palynology and Stratigraphy of the Mesozoic Khorat Group Red Bed Sequences from Thailand. Geological Society, London, Spe- 
cial Publications, 315, 69-83. https://doi.org/10.1144/SP315.6

[19] Young, R. and Young, A. (2012) Sandstone Landforms. Springer Science \& Business Media, Berlin.

[20] Turkington, A.V. and Paradise, T.R. (2005) Sandstone Weathering: A Century of Research and Innovation. Geomorphology, 67, 229-253. https://doi.org/10.1016/j.geomorph.2004.09.028

[21] Zhu, C., Peng, H., Ouyang, J., Hu, Z. and Li, L. (2010) Rock Resistance and the Development of Horizontal Grooves on Danxia Slopes. Geomorphology, 123, 84-96.

[22] Peng, H. (2001) Danxia Geomorphology of China: A Review. Chinese Science Bulletin, 46, 38-44.

[23] Qiu, J., Li, P., Zhang, F. and Li, P. (2015) Petrology and Spectroscopy Studies on Danxia Geoheritage in Southeast Sichuan Area, China: Implications for Danxia Surveying and Monitoring. Geoheritage, 7, 307-318. https://doi.org/10.1007/s12371-015-0160-1

[24] Luo, C. (2005) Regional Difference among Danxia Landform in Sichuan. Journal of Leshan Teachers College, No. 12, 134-138.

[25] Sichuan Bureau of Geology and Mineral Resources (1991) Sichuan Regional Geology. Geology Press, Beijing.

[26] Deng, B. (2013) Meso-Cenozoic Architecture of Basin-Mountain System in the Sichuan Basin and Its Gas Distribution. Chengdu University of Technology, Chengdu.

[27] Peng, H., Qiu, Z. and Pan, Z. (2014) Experimental Study on the Weathering Features of Experimental Study on the Weathering Features of Bedding Caves at Mt. Danxiashan. Scientia Geographica Sinica, 34, 454-463. 